\title{
EL JOVEN INDÍGENA EN CHIAPAS: EL RE-CONOCIMIENTO DE UN SUJETO HISTÓRICO
}

\author{
Tania Cruz-Salazar
}

Resumen. Este artículo analiza el nacimiento del joven indígena en el estado de Chiapas como un sujeto histórico, a partir de procesos económicos, políticos, migratorios y educativos como la crisis agraria de los ochenta, la explosión de la migración juvenil internacional, la escuela indígena y el modelo educativo intercultural. El método fue etnográfico; se realizaron entrevistas a profundidad en distintos lugares y tiempos a jóvenes hablantes de lengua indígena que reconocían su pertenenciaétnica. Los hallazgos permiten exponer condiciones, experiencias y procesos juveniles de muchachos y muchachas tseltales, ch'oles, cholanotseltales, mayaslacandones y tsotsiles.

Palabras clave: juventud, etnicidad, generación, educación y migración.

Enviado a dictamen: 05 de marzo de 2012

Aprobación: 25 de julio de 2012

Revisiones: 1

Dra. Tania Cruz Salazar, doctora en Antropología Social, CIESAS-Sureste. Temas de especialización: juventud, migración, género y generación. Correo electrónico: tcsalaza@ucsc.edu.
Abstract. This paper offers a discussion on the emergente of the Indigenous Youth as an historic Subject in Chiapas. I contextualize its recognition throught the analysis of economic, social and political processes ocurres between 1980 and 2005, those were, the agrarian crisis, the nternational youth migration explossion, the role of indigenous Schools and the establishment of the intercultural model education. Ethnography was the method to carry out indeep interviews in Chiapas, Florida and California from 2008 to 2012 in different times and spaces. The findings show youth conditions, experiences and processes among Tseltales, Ch'oles, Cholanotseltales, Mayas-Lacandones y Tsotsiles boys and girls.

Keywords: youth, ethnicity, generation, education y migration.

\section{Introducción}

$\mathrm{E}$ joven indígena como sujeto autor de su propia historia tiene un pasado reciente, aunque como actor social se le puede ubicar mucho antes. Me refiero a que en Chiapas el joven indígena fue un actor crucial desde 1950 para uno de los aparatos hegemónicos estatales que lo necesitó y lo formó como promotor cultural: la escuela indígena. Debido 
al vuelco en la historia del último cuarto de siglo se puede rastrear el nacimiento de un 'nuevo' sujeto en el marco de varios procesos de carácter económico, político y educativo. La crisis agraria de finales de los ochenta y su recrudecimiento en la década subsiguiente con el TLCAN, la guerra zapatista de 1994, junto a los desplazamientos forzados y los movimientos sociales posteriores, la explosión de la migración indígena internacional de 1998 al 2000 y la llegada del modelo intercultural en el 2000 contribuyeron al reconocimiento de este sujeto quien, a diferencia de aquel actor de los ciencuenta tiene agencia y consciencia de sí.

El objetivo del trabajo es contextualizar el nacimiento del joven indígena en Chiapas para contribuir a la veta de estudios de las juventudes indígenas indicando la transformación disciplinar en la antropología, hecho que ha permitido re-conocer a este 'nuevo' sujeto. Prioritario es ubicar el tema en un campo transdisciplinar como el de los estudios culturales y establecerlo en la agenda académica regional. Los enfoques de juventud permiten hacer estudios transversales que hoy son fundamentales para problemas actuales en el estado: desintegración familiar, desestructuración del campesinado, alteraciones en los sistemas de cultivo y en las producciones locales, cambios en los patrones alimenticios, sustitución de la exogamia por la endogamia, postergación de la unión y la procreación, evasión de compromisos comunitarios, rupturas en las estructuras de parentesco, alteración de patrones y saberes culturales, discontinuidad en los rituales y conflictos generacionales, entre otros.

La gestación de juventudes en torno a la etnicidad, a las innovaciones culturales y a la flexibilización identitaria son aspectos relevantes que hablan del cambio en las visiones de los indígenas chiapanecos contemporáneos. Lo juvenil entre los indígenas es un fenómeno social que va más allá de criterios biológicos $\mathrm{y}$, aunque toma la etnicidad como referente central, no lo hace de modo prioritario, ${ }^{2}$ pues su tratamiento no es parejo al de otras condiciones suyas porque la clave para el tránsito cultural es la condición étnica. Un asunto-legado del discurso zapatista donde el mundo da cabida a otros mundos. Los indígenas que nacieron y crecieron con el estandarte del diálogo cultural y del orgullo étnico experimentan el mundo bajo el paraguas de la transculturalidad, lo que les otorga un cierto grado de empoderamiento, agencia, movilidad, presentación y autorrepresentación en la vida cotidiana.

El argumento central es ver al joven indígena chiapaneco como figura paradigmática ya que, al nacer de procesos que revolucionaron las relaciones interétnicas, hasta cierto punto es el 'nuevo' joven indígena quien ha oxigenado dichas relaciones. Él es la metáfora del cambio social en Chiapas (Feixa, 1998). Las reflexiones aquí presentadas se basan en un trabajo de varios años basado en la revisión de archivos, bibliografía y hemerografía. Las técnicas de investigación fueron la etnografía multisituada, la observación participante, las pláticas informales, las entrevistas a profundidad y las entrevistas semiestructuradas. Los instrumentos fueron el cuestionario, la guía de observación y la pauta de la entrevista. La investigación de campo fue llevada a cabo en tiempos y lugares distintos. Los informantes fueron contactados en Chiapas (2008-2010), Florida (2009 y 2011) y California (2011 y 2012). Todos fueron jóvenes hablantes de lengua indígena, tseltal, ch'ol, ch'olanotseltal, tsotsil y maya lacandón. El universo de estudio lo componen 60 casos de jóvenes indígenas chiapanecos de 17 a 29 años. Los casos son variados, porque unos responden al perfil del joven migrante internacional, otros al del joven universitario intercultural y otros al joven indígena urbano. El texto abre con el enfoque del trabajo al tiempo que ofrece un conciso estado del arte para los estudios sobre juventud y juventudes indígenas. El siguiente apartado aborda los procesos que permiten re-conocer el nacimiento del joven indígena en Chiapas. Agrupo cronológica y temáticamente los eventos que suceden en el estado y que denotan la emergencia de dicho sujeto. Los testimonios juveniles ilustran cada proceso de manera sistemática. El trabajo cierra 
ofreciendo consideraciones generales sobre el estudio de las juventudes indígenas.

\section{Aproximaciones a las juventudes indígenas}

La juventud es una etapa, una condición o un estilo de vida que varía temporal y espacialmente de acuerdo al grupo cultural que la reconozca y la viva, por tanto, tiene un carácter transitorio, situacional y cambiante. Como noción hegemónica la juventud es universal, dado que tiene historicidad y evoca un suceso que se presenta en todas las sociedades (Hall, 1905; Mead, 1985). Es una invención de la sociedad industrial, hija de la modernidad y se consolida después de la segunda guerra mundial (Aries, 1973). Con la expansión del modo de producción capitalista se crea la separación niñosadultos dando cabida a nuevas clases sociales y nuevos espacios para la cultura adolescente. A principios del siglo XX la escuela, el servicio militar y la sociedad de consumo fueron los centros de preparación juvenil. Coleman (1961) señala rasgos específicos de aquella naciente sociedad adolescente documentando intereses, actividades y lenguaje particularmente opuestos al mundo adulto de la época.

Desde entonces a la fecha varias escuelas de pensamiento abordaron el tema juvenil desde disímiles marcos conceptuales. ${ }^{3}$ Para este trabajo es útil la corriente de los estudios culturales desarrollados por la academia hispanoablante, dado que abarca la diversidad juvenil y sus manifestaciones explícitas en torno a las identidades juveniles rurales, campesinas e indígenas (Feixa, 1998; Duarte, 2000; Margulis, 1994; González, 2004; Belviqua, 2009). En América Latina la atención a lo juvenil inició en las primeras décadas del siglo XX desde la ensayística y la literatura, aunque el enfoque central en el sector tomó fuerza en los cincuenta, cuando la psicología y la sociología explicaban a los jóvenes, bien como desviados, bien como problemáticos (Feixa y González, 2005; Pérez, 2006). No es hasta la década de los sesenta, con los movimientos estudiantiles, cuando la sociología institucionaliza lo que hoy se conoce como estudios de juventud. Desde la antropología y los estudios culturales distintas miradas toman lugar en los ochenta, entendiendo a la juventud más allá de la edad, como una construcción sociocultural que explica varias maneras de ser joven desde la compleja producción cultural (Margulis y Urresti, 1996). Bajo este enfoque se engloban trabajos sobre lo juvenil latinoamericano en los últimos treinta años. Su relación con la cuestión étnica ha sido una discusión más reciente que ha producido diversos enfoques para explicar la emergencia del período juvenil en los grupos étnicos, etapa apenas re-conocida no sólo por la academia sino por diversas etnias.

En 2004 Nueva Antropología publicó el trabajo "Juventud rural. Trayectorias teóricas y dilemas identitarios", de Yanko González, donde se advierten los límites de aquella nueva veta de estudio incluyente de lo campesino pero no necesariamente de lo indígena. La contradicción señalada entre la carga semántica de la juventud en tanto "fruto del capitalismo, la industrialización, la urbanización y la modernización”, y lo rural como "arcadia atrasada, reactiva, conservadora, homogénea, con un solo actor protagónico: el campesino, hombre y adulto" (González, 2005: 155) explica la liminalidad de los estudios sobre juventud(es) rural(es) al tiempo que reconoce al joven rural como agente de cambio y/o desarrollo en el período de industrialización latinoamericana con la 'nueva ruralidad'. Un año más tarde, Feixa y González $(2005,2006)$ registran la ausencia de trabajos sobre infancia, adolescencia y juventud en los horizontes indígenas y rurales, criticando el sesgo etnocéntrico de los enfoques de juventud que no habrían permitido elaborar reflexiones al respecto. Como resultado del encuentro "A criança e o jovem na America Latina”, celebrado en 2011, estos autores escriben "Territorios baldíos: identidades juveniles indígenas y rurales en América Latina" y "The Socio-Cultural Construction of Youth in Latin America: Achivements and Failures", trabajos pioneros 
que sitúan el asunto en la academia. Para enfatizar la urgencia por reconceptualizar la infancia y la juventud desde una perspectiva latinoamericana, los autores estipulan la necesidad de un enfoque diacrónico y transcultural. Feixa y González (2005) revisan puntos cruciales como l) el supuesto de que la mayoría de la población latinoamericana inicia su vida laboral y sexual a temprana edad por su extracción socioeconómica, lo que explicaría la omisión sociohistórica de la infancia y la juventud, así como la ausencia de comunidades de estudios sobre infancia (infantólogos) y juventud (juvenólogos) de modo separado; 2) la emergencia de las juventudes urbano-populares y su estudio en los ochenta, como antesala de las juventudes indígenas y rurales de los noventa, en los procesos de modernización e hibridación cultural; y 3) la desatención de los estudios socioculturales por la dimensión generacional, debido a los enfoques utilizados para estudiar a las comunidades indígenas campesinas y rurales. En el caso de la antropología mexicana, Feixa encuentra que, en 1986, autores como Acevedo ya habían criticado esta tendencia diciendo que:

[...] hablar de indígenas siempre implicó hablar de los líderes o chamanes, oradores o curanderos, artesanos o milperos, macehuales. El sujeto indígena de la literatura etnológica siempre ha sido el adulto varón... Pero hablar de los indigenas ha significado hablar poco de los niños indígenas adolescentes o de la gente joven, los que son el futuro de la población no han estado involucrados en términos económicos ni culturales (Feixa, 2006: 7-8).

Las lagunas respecto a lo joven dentro de lo rural y lo indígena explican cómo otros sujetos subalternos fueron invisibilizados por los enfoques del momento que interpretaron las comunidades rurales y sus miembros a partir de sus ocupaciones, a saber, la agricultura y la artesanía, actividades pilares de la economía campesina (Feixa, 2006). La antropología latinoamericana reprodujo en sus estudios de juventud el adultismo, el estatismo, ${ }^{4}$ el sexismo, el racismo y el colonialismo, al no desnaturalizar la representación hegemónica de la juventud occidental masculina urbana de clase media no indígena. Por ser un constructo de la modernidad — siglos XVIII y XIX — la juventud necesita ser cuestionada, relativizada y superada para entonces acercarse a sociedades fuera de la lógica 'moderna occidental' y desmantelar lecturas estáticas y estériles como la del indígena tradicional y cerrado (Foley y Holland, 1996).

En México los trabajos sobre juventud indígena han sido realizados desde enfoques como la desventaja, la interculturalidad, lo fronterizo, la vulnerabilidad, la transculturalidad, la migración y la globalización (Pacheco, 1999; Pérez Ruiz, 2008 y Urteaga, 2008). Particularmente las disciplinas Educación, Antropología y Psicología han abonado esta veta de estudios. ${ }^{5}$ En "Juventud indígena en desventaja. ¿Cuál es el futuro de los jóvenes indios?" Pacheco (1999) abre la discusión contemplando tres aspectos importantes para el reconocimiento de esta juventud: el crecimiento demográfico de la población indígena, especialmente de su juventud, las fallas del sistema educativo enfocado en la castellanización de la población indígena en edad escolar y la nueva ocupación jornalera agrícola de los jóvenes indígenas debido a la reindustrialización mundial. Los tres sucesos que la autora expone confluyen en la salida de estos jóvenes a las ciudades, hecho fundamental para la emergencia de la juventud indígena. Urteaga (2008) abona dicha discusión puntualizando que el crecimiento demográfico juvenil en México es generalizado, la migración se ha afianzado y diversificado, la participación de la juventud en la cultura de la migración es clave, el curso de la secundaria se ha vuelto obligatorio y la llegada de la telesecundaria y los medios de comunicación —radio y televisión - a las comunidades indígenas, han sido decisivas para la emergencia de "algo que puede denominarse período juvenil entre la población 
étnica que habita en los pueblos como en las ciudades" (Urteaga, 2008: 7).

Jóvenes indígenas y globalización en América Latina (Pérez Ruiz, 2008) es el primer esfuerzo sistemático que nos ofrece una lectura fresca sobre la materia. Afirmar "la existencia de este sector como segmento diferenciado dentro de los pueblos indígenas, tanto en comunidades rurales como urbanas" (Pérez Ruiz, 2008: 20), es la aportación más sustancial de esta obra, resultado de una docena de trabajos realizados a lo largo de América Latina con jóvenes indígenas mexicanos, chilenos, ecuatorianos, bolivianos, colombianos y guatemaltecos. Los descubrimientos que más destacan son: 1) La existencia del concepto joven en lengua indígena, palabra referida a una etapa que inicia con la madurez biológica y concluye con la madurez social, es decir, la edad y los aspectos fisiológicos son las constantes mientras que los contenidos y modos significativos - culturalesson las variables. 2) Lo joven en los pueblos indios se encuentra construyéndose en medio de una tensión entre lo tradicional y lo moderno, por lo que se está reformulando a partir de referentes nuevos que actualizan lo tradicional. 3) Los jóvenes indígenas construyen nociones de juventud altamente heterogéneas por lo que es necesario abordar la diversidad en los procesos de socialización, la familia y la vida comunitaria que están siendo desplazadas por la educación, la migración, la religión, las relaciones interétnicas, los medios masivos de comunicación e información y el destierro por pasados episodios de guerra. 4) La desobediencia juvenil, la confrontación generacional y la pérdida de control comunitario sobre ellos han situado a la juventud indígena como problema social dentro de los pueblos, especialmente ante los ojos de las generaciones adultas (Pérez Ruiz, 2008).

Identifico dos líneas de trabajo en los recientes estudios sobre juventud indígena, los cuales abordan contenidos de lo étnico juvenil, frente aquellos que señalan lo cambiante en los grupos étnicos y su asociación con las experiencias de lo juvenil moderno: léase aparición de nuevos estilos, culturas e identidades juveniles. Pocos son los trabajos que testimonian la existencia de procesos juveniles indígenas asociados a cargos, compromisos comunitarios o roles de género: los trabajos de Pacheco $(1997,1999)$ han ofrecido reflexiones al respecto. García Leyva (2005) ha enfocado su trabajo en la producción cultural juvenil indígena $\mathrm{Na}$ Savi, especialmente la música de la montaña guerrerense (2012). García Martínez (2009) estudió el nacimiento de la juventud indígena entre totonacos de Veracruz y definió a la juventud indígena como:

[...] un periodo vital reciente [...] marcado en términos biológicos con la entrada a la pubertad, y en términos sociales con la interrupción del tránsito del estado infantil al adulto de acuerdo a la ruta vital establecida por la propia cultura. Este periodo vital [...] se caracteriza por la generación de un nuevo estatus al interior de la sociedad y el surgimiento de procesos identitarios de autopercepción y heteropercepción (García Martínez, 2009: 1).

Otros trabajos destacan los cambios culturales asociados a la globalización, la migración y los avances tecnológicos, entre éstos se encuentra el de Gama (2007) "Mazahuacholoskatopunk", donde la hibridez cultural de los chavos mazahuas es el motivo central de la documentación que aporta. La ascendencia mazahua forma parte importante del ser étnico entre estos jóvenes, sin embargo, esta dimensión identitaria se mueve a la par de las otras sin establecerse de modo prioritario. Los trabajos compilados por Pérez Ruiz (2008) también ilustran los cambios asociados a la modernidad. Estos son estudios realizados con jóvenes indígenas sin enfoques sobre juventud pues acuden al marco referencial de la globalización y sus efectos en el ámbito cultural. El trabajo de Eva Fischer sobre jóvenes aymaras de Upinhuaya destaca no sólo la importación 
de conceptos castellanos para definir los rangos etarios, sino toda la singularidad que la cosmogonía aymara imprime a las vivencias de juventud en el mundo indígena. Varios trabajos sobre migración han recuperado las manifestaciones juveniles indígenas y sus cambios dentro de las comunidades: en esta línea están los escritos de Ricardo Falla, especialmente sus últimos dos libros Juventud de una comunidad maya (2006) y Migración internacional retornada. Juventud indígena de Zacualpa (2008) y el trabajo de Ruiz Lagier (2007) sobre los jóvenes migueleños de La Gloria, Chiapas, donde documenta las nuevas formas en que los q’anjobales hijos de migrantes guatemaltecos están viviendo la juventud. Junto a éstos, están los trabajos de investigadores jóvenes, estudiantes de licenciatura y posgrado. ${ }^{6}$

En "Mudándose a muchacha. La emergencia de la juventud en indígenas migrantes" (2009) documento las prácticas de juventud de muchachas indígenas migrantes tsotsiles y tseltales en San Cristóbal de Las Casas, Chiapas. El reconocimiento de su ser juvenil en relación al género, especialmente en sus ideas y experiencias en torno al cortejo, se da mediante el noviazgo y la elección de pareja. La experiencia transformadora de la migración en la población indígena femenina permite observar una moratoria social en la que ellas mismas se ubican incluso después de haber estado casadas o de ser madres. En "La norteada juvenil. Representaciones de la migración tsotsil" (2012) esbozo un conjunto de representaciones coexistentes en el contexto de la migración mexicana primero, y de la migración indígena de jóvenes varones tsotsiles después, dando cuenta de nuevos estilos juveniles transculturales. La apuesta es entender el proceso migratorio como prefigurativo de estilos juveniles indígenas. Las experiencias migratorias de los jóvenes tsotsiles revelan cambios generacionales y genéricos asociados a la recomposición del agro chiapaneco, pues resumen la reconfiguración de prácticas culturales comunitarias en general y de la estructura familiar indígena en particular.

La etnicidad en lo juvenil cobra fuerza a finales de los noventa, justo cuando su participación fue decisiva en la migración internacional (Urteaga, 2008, 2010; Cruz, 2009, 2012). Por tanto, es necesario que en los actuales estudios de juventud tomemos en cuenta procesos decisivos que expliquen la aparición de estos tránsitos. La reflexión aquí expuesta discute con la literatura previamente citada tratando de vincular la aparición-reconocimiento del joven indígena en Chiapas en el marco de varios procesos que agrupo temporalmente: 1) la crisis agrícola y las migraciones indígenas, 2) la escuela indígena y el modelo educativo intercultural.

\section{Procesos en la emergencia del joven indígena chiapaneco}

\section{Crisis agrícola y migraciones indígenas (1970-2000)}

Mi papá cosechaba papa, calabacita, chile y frijol. Como no teníamos hermanos, todas las hijas íbamos con él desde chiquitas, también mi mamá. Tenía bastante tierra que había dejado mi abuelito. Él trabajaba su parcela y vendía las rejas de verdura acá en San Cristóbal. Luego ya no alcanzaba para seguir trabajando la tierra, decidió ir a 'los estados' en el 93. Después perdimos la tierra por la deuda del coyote, él se enfermó allá le salió una bola en la garganta y no podía hablar bien, le fue creciendo. Un tío abusivo nos dio prestado el dinero con interés para regresar a mi papá pero se quedó con las 20 hectáreas porque la cuenta subió mucho (Sebas, 21 años, tsotsil, 2009).

El testimonio de Sebas ilustra de modo sintetizado la crisis de una familia campesina tsotsil Chamula antes del estallido del EZLN. Rus (2002) argumenta que el proceso de declive del modelo de agricultura de plantaciones tuvo lugar de 1960 a 1980. La devaluación 
del peso, la caída de los precios de los productos y el incremento de costos para obtener fertilizantes abonaron la crisis dando como resultado el paro de la inversión en la propia tierra. En 1970 muchos compraron ganado e iniciaron potreros y para 1990 los agricultores ya habían abandonado sus tierras. Los nuevos granjeros - pequeños propietarios y ejidatarios - reactivaron la producción para lo que necesitaron mano de obra (Rus, 2002). En ese momento el crecimiento demográfico indígena experimentó una explosión demográfica sin igual y sobraban manos para estos trabajos que estaban siendo ocupados por guatemaltecos. ¿Qué pasó entonces? Una oleada de indígenas alteños, migrantes estacionarios extrabajadores de las fincas en Ocosingo, Altamirano, Comitán y Las Margaritas se fueron en busca de tierras a la Selva Lacandona formando las nuevas colonias agrícolas. Leyva y Ascencio (2002) explican que ésta fue la segunda oleada pues afirman que otra tuvo lugar en 1930. Con el objetivo de colonizar para tener tierra y casa, esta segunda oleada impactó a la región. La población selvática aumentó de "5,000 en 1970 a 250,000 en la década de 1990” (Rus, 2010: 2). ${ }^{7}$

Mi abuelo era de Chamula un pueblito de las orillas. Mi papá de Palenque, bueno de un ejido, luego vino a Chancalá de donde es mi mamá. Teníamos cafetales antes. Cosechábamos, pero luego vino el agua y lo chingó todo. Bajo mucho el precio del kilo y ya no se podía ganar nada. Él se fue en 1995, luego lo llevó a mi hermano mayor y mi hermano me trajo a mi (Fili, 24 años, tseltal, 2011).

Las palabras de Fili muestran las estrategias familiares y generacionales para la reproducción del modo campesino, entre las que siempre ha estado la movilidad poblacional. Cuandollegó el Tratado de Libre Comercio, los pequeños productores no pudieron contrarrestar ni la competencia ni el recorte de subsidios al campo (Villafuerte, 2008; Fox, 2010).
Mi papá fue jornalero, mi hermano también, yo de chiquito trabajé la tierra con mi jefe pero en su parcela ahí en la casa. Todos mis hermanos, todos los kichanes de acá sabemos trabajar la tierra, pero yo, ya no quiero. Nunca trabajé de pizcar en los files de acá, mis tíos que vinieron antes sí pero yo no (Rica, ch'olanotseltal, 21 años, 2012).

Después del año 1994, la crisis recrudeció. El estallido de la guerra y la respuesta gubernamental con la paramilitarización estatal contribuyeron a enfrentamientos, expulsiones forzadas, tomas de tierra y conflictos dentro de varias comunidades. Aunque el objetivo del levantamiento zapatista fue reforzar el sentimiento de comunidad tomando las tierras de los hacendados, después del 1995, seguir comprometidos con la política de determinación y orgullo étnico, no fue fácil pues implicó muchas restricciones (Mancina, 2011). En palabras de Timoteo el asunto fue así:

Entré al movimiento en 1995 y estuve ahí hasta el 98. Mi abuelito estuvo en la revolución antes, yo tenía ocho años. Él me dijo que tenía que apoyar la causa y por eso entré pero era mucho trabajo, dormíamos poco y no tenía para comer. Aprendí bastante, nos entrenaban todo el día, horas y horas. Era duro. Dejéel movimiento, firmé unos papeles que al regreso serviré otra vez, me dieron permiso y me vine pa' acá en el 1998. Eso sí, seguimos estando con el movimiento, o sea, estamos allá, cualquier cosa que pase yo estoy allá con ellos (2011).

Los proyectos juveniles de migrar al norte fueron para las comunidades zapatistas un gran reto, pues tuvieron que negociar con las búsquedas de las nuevas generaciones y aceptar que la idea colectiva de trabajar para la comunidad no les interesaba tanto a los jóvenes como la idea de irse a Estados Unidos. Esto fue muy criticado por las bases zapatistas porque significó la superposición del proyecto individual-familiar por 
encima del comunal (Aquino, 2009). Entre los jóvenes que entrevisté tres posturas llaman la atención: 1) la negación o desconocimiento del asunto político zapatista: "no sé, nadie de mi familia se interesó"; 2) la asociación del movimiento a una 'moda': “iy tú qué opinas del zapatismo?" "iYo? Nada, estuvo chido por un tiempo pero luego pasó de moda" (2011); y 3) la transición de esta moda a otra, la de migrar al norte: "mejor venimos a California”.

Las tensiones entre las generaciones zapatistas y los deseos juveniles de ir al norte explican las diferencias entre las visiones, Aquino (2009) las llama "lógica militante vs lógica migrante." La primera generación veía redención y ruptura comunal entre los camaradas que salieron al norte, mientras que las siguientes generaciones ven en la migración la 'posibilidad' de progreso económico para la familia o para sí mismos. En cualquier caso, la rebelión zapatista dejó un legado histórico para las relaciones interétnicas entre mestizos e indígenas dentro y fuera del estado (Cruz, 2012). Los indígenas que nacieron y crecieron con la filosofía de un mundo en donde quepan otros mundos son los que Mancina (2011) nombra "los hijos o nietos de exacasillados ejidatarios", miembros de la primera generación del orgullo étnico en Chiapas. Ellos son los primeros interesados en salir, estudiar, migrar o cambiar el rumbo de su historia como buenamente pueden.

Yo alcancé a vivir la pobreza hasta los 12 años. Recuerdo que me ponía unas playeritas y a veces se me rompían aquí en la panza, mi pantalón y mis playeras todas rotas, luego andaba mis huaraches en vez de zapatos, todo, no me ponía zapatos porque a mi papá no le alcanzaba. Mi papá es agricultor, lo que cosechaba nada más era para el consumo, no alcanzaba para vender, a veces vendía pero no era tanto, no daba para tanto [...] mis primos me empezaron a decir que en México no había futuro ni nada y lo que ganábamos no era nada, digámoslo así era una miseria. Lo que ganábamos no nos daba para nada, sólo para comer y ya así empezaron a decir que en los Estados Unidos se gana más (Darinel, 22 años, tseltal-tsotsil, 2010).

La migración juvenil indígena internacional resulta de la crisis agrícola que los abuelos y padres vivieron y de la necesidad de ingresos para la reproducción social, es decir, de la búsqueda para reproducir el papel del varón jefe de familia. Entre los entrevistados, varios hablaron de la necesidad de obtener recursos para desposar a una muchacha, mantener a una familia o hacerse con bienes y poder ofrecer "algo" en el futuro - especialmente terreno y casa-. Estos motivos vinculan la lógica generacional y de género de estos jóvenes varones indígenas.

No tenía nada, para comprarme zapatos nuevos o pantalón pasaban 2 o 3 años. Aunque mi mamá era maestra bilingüe no le alcanzaba. Con huarache de cuero roto andaba yo. Menos tener novia icon qué invitar pues? Y luego mis hermanitas iquién las iba a ayudar a estudiar si mi papá ya tenía otra mujer? Tuve que venir, yo quería seguir en la preparatoria ya había empezado en el COBACH de Sancris pero no lo pude terminar (Dario, maya-lacandón, 23 años, 2011). Yo me junté allá pero a esa edad yo no tenía nada, no tenía ni un cinco, a veces pensamos que juntarnos es fácil, pero no es fácil. Había estudiado hasta el $\mathrm{COBACH}$ y me di cuenta que quería estar con alguien ya, pero a esa edad — tenía yo 14 años-, era pura calentura, piensas que es fácil, pero no es fácil. Dice el dicho que el casado casa quiere, pero eso no lo pensé, me junté y luego me dí cuenta que no funciona y me dijo mi mamá, te dije que no te juntaras a muy temprana edad, pero eso no lo pensé, le dije ok, me voy, luego me cansé y le dije a mi mamá isabes qué? Me voy. No teníamos dinero, pero con su ahorro me vine, me dio todo. Primero me fui a Arandas, Jalisco a trabajar el mezcal luego ya vine a California (Arsemio, 25 años, tseltal 2011). 
Una vez experimentada la migración, la visión de mundo cambia y muchos de estos jóvenes centran su vida en torno a la moratoria social que la juventud brinda como etapa. Entonces, las críticas al previo modo de vida inician. Las palabras de Arsemio explican ese cambio de visión a partir del autojuzgamiento y su pasado. El matrimonio a temprana edad y la formación de una familia hizo por décadas que los y las muchachas se vieran como adultos responsables, señores del mundo institucionalizado a pesar de su edad, sin embargo, la experiencia migratoria les ha hecho cambiar esta forma de entenderse a sí mismos. ${ }^{8}$ Las búsquedas juveniles menos localizadas en el campo resultaron de aprendizajes heredados por quienes experimentaron las primeras salidas al norte. Ahora también las muchachas están yéndose al norte y su participación laboral es cada vez más evidente, así como lo es su ingreso a los espacios educativos. ${ }^{9}$

"Yo vine porque allá en mi pueblo habían como tres o cuatro que ya se habían venido para acá y regresando nos comentaron cosas de Estados Unidos y todo eso" (Demetrio, tsotsil, 22 años, 2011). La cultura de la migración, el ir a probar suerte, se expandió pronto entre los jóvenes indígenas de Chiapas. Se convirtió en una moda y en un rito de paso que para muchos sustituiría a la preparatoria (Cruz, 2011). La migración fue el detonante para la cada vez más visible presencia del joven indígena. Su participación en el éxodo internacional evidenció su interés por construirse futuros o posibilidades que el mismo estado les había negado.

Yo me vine porque estaba en la escuela, estaba en la prepa y no había dinero para seguir estudiando pues somos ocho hermanos, cuatro varones y cuatro mujeres. Mi papá ya había venido también. Estábamos bien en la escuela pero no había dinero, veía que a mi papá le estaba costando y ayudaba a mis hermanos y hablé con mi hermano que ya estaba aquí en California. Le dije que quería venir para acá también.
Me dijo, ¿Ya le dijiste a papá? Le dije no, pero te estoy diciendo anticipadamente para que tú primero me digas y luego se lo diga a papá. Yo tenía mucha desesperación porque no alcanzaba el dinero en la escuela y para no gastar nos íbamos a la biblioteca a rentar libros para no sacar copias, entonces no alcanzaba, se los llevaban todos y a sacar copias (Eulalio, ch'olanotseltal, 20 años, 2011).

La escuela indígena y el modelo intercultural (1980-2005)

En 1951 se fundó el primer Centro Coordinador Indigenista (CCI) en Chiapas, que tenía como misión llevar "el desarrollo cultural" a las comunidades tsotsiles y tseltales. Buscaba un cambio de la cultura indígena hacia un modelo de sociedad o cultura urbana. Para lograrlo se propuso que el instructor fuese originario de la comunidad y capaz de dictar la clase en lengua indígena, y para ello se prepararon jóvenes de la región Altos de Chiapas para que fungieran como promotores del cambio cultural desde la escuela indígena, surgió así la figura del "promotor cultural bilingüe" responsable de la enseñanza de la lectoescritura en lengua materna y en castellano (Bastiani, 2012: 12).

La escuela es el aparato estatal más eficaz para formar modelos juveniles. En el caso chiapaneco, la escuela indígena lo fue al formar maestros bilingües, promotores culturales y estudiantes. ${ }^{10}$ En la actualidad es uno de los espacios de inclusión y al tiempo "se convierte en un proceso de exclusión debido a la práctica de pedagogías de subordinación donde la juventud indígena es objetuada" (Pacheco, 2012: 1). Los modelos educativos — castellanización (1950), bilingüe bicultural (1970) e intercultural bilingüe (2000) - concertaron una política educativa dirigida 'al joven varón indígena'. El objetivo fue castellanizarlo para asegurar su acercamiento a la vida urbana mestiza. 
Mi papá nació en 1965 y se hizo maestro bilingüe a los 20. Somos tseltales de La Siria, tenemos tierra aunque la única de la familia que cosecha un poco de café es mi abuelita, mi papá sigue sembrando un poco pero casi ya no. Yo hice la licenciatura en pedagogía en la Unach. Ya casi me titulo de la Maestría en Educación Intercultural de la UPN, tengo 24 años y soy maestro bilingüe en la Escuela Secundaria Técnica de la comunidad más cercana a mi pueblo (Arcadio, tseltal, 24 años, 2009).

El caso de Arcadio muestra la reproducción generacional y de género de la educación indígena. Entre las aspiraciones de trabajo de los jóvenes indígenas persiste la de ser maestro como una imagen poderosa a la que se guarda respeto por el conocimiento adquirido. La escuela indígena en Chiapas ha jugado y juega un rol trascendental porque al tiempo que ofrece 'mejoría' lo hace bajo la 'descalificación' de los saberes tradicionales indígenas (Bastiani, 2012; Hernández, 2012). Aunque la escuela siga representando mejor estatus, la posibilidad de ascender socialmente hablando, para muchos adultos mayores de la comunidad significa riesgo o discontinuidad cultural.

La llegada de las telesecundarias a las comunidades indígenas, ocurrida en $1981,{ }^{11}$ representa un quiebre en las dinámicas de aprendizaje local que aseguraban herencia cultural. La telesecundaria como espacio educativo supuso para muchos una ruptura con la enseñanza colectiva de la comunidad que fungía en tanto espacio primario de socialización para niños, quienes se desarrollarían y aprenderían en su entorno propio. ${ }^{12}$ Lo contradictorio en aquel entonces era que la escuela indígena, bajo el modelo de castellanización primero y bilingüe bicultural después, significó la negación de la identidad cultural indígena aunque el programa pretendiera lo opuesto (Bastiani, 2012). Esto sentó las bases para asociar la lengua indígena al retraso o a impedimentos para el desarrollo de habilidades o capacidades en el mundo mestizo. Así, aprender 'castellano' para 'mejorar' se esparció en el pensamiento comunitario indígena de las previas generaciones que aún comulgan con este discurso:

A veces me siento raro hablando en tzeltal porque mi papá siempre me prohibió hablar en dialecto iNo quiero que hables así! Me decía. A lo mejor se avergonzaba, porque me decía el día que te escuché hablando así, te voy a agarrar a cinturonazos, no quiero que hables eso, yo quiero que hables español, siempre me decía así, cuando hablaba con mis primos, hablaba diferente, hasta ellos se agüitaban, al menos que mi papá no estuviera ahí entonces sí hablaba con confianza en tzeltal con ellos, pero a veces también mis tíos me acusaban, tú hijo estuvo hablando así le decían y entonces mi papá me llamaba la atención, me regañaba. Él siempre me hablaba en español. Entre él y mi mamá hablaban tzeltal y mis hermanas no crecieron así, ellas sí hablaban puro tzeltal (Darinel, tseltal, 24 años, 2008).

Según Darinel, la intención de su padre era que élllegara a la fluidez. Se preocupaba por su futuro y por ello decidió que sólo a él se le hablara en castellano. Como era el hijo varón de una familia con cuatro hijos, de los que tres eran mujeres, vemos que la forma de pensar y actuar del padre concordaba con la visión tradicional de género cuyos modelos orientan a la salida de casa de los varones y a la permanencia de las mujeres. También significa que los varones indígenas son los encargados de la negociación con el mundo urbano mestizo para la reproducción de la jefatura del hogar. ${ }^{13}$

El caso de Ignacio, un joven de 24 años maya lacandón, difiere ligeramente del de Darinel. Su madre, una maestra bilingüe tseltal de 45 años, tuvo dos hijas además de Ignacio. Ella le pagó a Ignacio la escuela desde la primaria hasta el cuarto año de preparatoria. A todos sus hijos les enseñó su idioma, además el padre, un hombre maya lacandón, también lo hizo. 
Los tres hijos son trilingües porque todos estudiaron en escuelas mestizas. Cuando Ignacio se encontraba en la preparatoria se dio cuenta de que su madre no podía seguir pagándole la escuela por lo que decidió migrar a EE.UU. y pagar los estudios de preparatoria y universidad a su hermana más pequeña (notas de campo, 2011). La mayoría de los entrevistados fueron en algún momento de sus vidas migrantes internos por motivos escolares. Quienes estudiaron la preparatoria lo hicieron fuera de su comunidad o ejido, y muchos de ellos se formaron en telesecundarias: ¿Y qué pasa después de la telesecundaria? No mucho, porque hay que migrar para seguir estudiando ya que "en la comunidad no hay nada después de la secundaria, bien te sales o te casas" (Carmelita, tsotsil, 20 años 2009). La mayoría de las escuelas preparatorias o de bachilleres están en las cabeceras municipales o en las ciudades más grandes y, como bien ilustró Ignacio, la educación necesita de inversión, insumos, libros, cuadernos y dinero para poder acceder a ella. No olvidamos que se han echado a andar varios programas para lograr aquello que la Coneval ha publicado a partir de su más reciente evaluación de consistencia y resultados 2010-2011: "el incremento de 40\% de la movilidad socioeconómica de jóvenes beneficiaros del Programa Oportunidades". Este programa, que entró en vigor en 1998, aumentó la población en edad escolar que asiste a la escuela en las comunidades porque, además de ofrecer las becas y los desayunos a los hijos que asisten a la escuela, se impuso una sanción de restricción de la beca a las familias que no los enviaran. En el caso de Chiapas, los niños comunitarios bajo el cuidado materno son los becados; los niños migrantes urbanos, quienes viven como vendedores ambulantes o en situación de calle, no asisten a la escuela. Los adolescentes o jóvenes indígenas que salen de sus comunidades regularmente lo hacen sin estos apoyos y cuando se van a estudiar la preparatoria todo es más difícil porque, además, están sin su entorno familiar y comunitario. Aún así, hay muchos jóvenes del corazón de la Selva que se van a Ocosingo para estudiar el bachillerato, otros de la región Altos dejan su comunidad y se van a San Cristóbal de Las Casas, los muchachos de la Sierra se dirigen a Tapachula, los de la Fraylesca a Villaflores y otros llegan hasta Tuxtla Gutiérrez, es decir, quienes pueden, hacen un gran esfuerzo por salir y buscar su destino en la educación superior formal.

Ni la secundaria, ni la telesecundaria, menos aún la preparatoria, cuentan con lo que alguna vez los programas de educación bilingüe y bicultural propusieron: una educación igualitaria. Bastiani (2012) demuestra cómo en la región ch'ol el modelo de castellanización transitó al bilingüe bicultural y luego al bilingüe intercultural sin mucho cambio. Con los testimonios de los profesores y la documentación de la práctica docente en el aula, el autor muestra cómo la idea de enculturar al alumno aún persiste. Otros trabajos más recientes están documentando el racismo y maltrato persistente en las escuelas secundarias indígenas (Hernández, 2012). Así pues, vemos que una década y media después del estallido del EZLN, la propuesta de cambio de modelo educativo, no sólo para Chiapas sino para todo el país, tiene deficiencias y desventajas.

En 2005 nace la primera universidad de corte intercultural inaugurada con la intención de ofrecer instrucción escolar y cuyos ejes centrales fueran las lenguas y las culturas indígenas. ${ }^{14}$ Este proceso de renovación educativa, con un discurso abierto y políticamente comprometido respecto al diálogo intercultural de modo parejo-horizontal, contribuyó decisivamente al nuevo panorama juvenil indígena. Los jóvenes que han ingresado a este espacio educativo están aprendiendo el estilo de vida del joven moderno universitario. Con ello han capitalizado varios aprendizajes tecnológicos. Las carreras ofertadas tienen como ejes la gestión de saberes, la recuperación y promoción de las lenguas, el buen vivir y la investigación aplicada. Esto, bajo los rubros del discurso intercultural 
institucional que, como bien señala Zebadúa (2012), "ha transformado a los/as jóvenes que ingresan" en sujetos étnico-históricos, sujetos empoderados y sujetos solidarios, pues el discurso intercultural:

[...] reconoce al estudiante rural e indígena como un sujeto que tiene un valor histórico; que toda la historia étnica que traen consigo mismos vale como una secuencia de tiempo, si se quiere alternativa, a la misma historia occidental [...] coloca la dignidad del sujeto como parte de la consecución de ese lugar en la historia y, a partir de ahí, genera justamente poderes ganados por los sujetos a partir de su toma de conciencia [...] el ser solidario y colectivo es una apuesta a la transformación estudiantil y por tanto se apela aquí a las viejas tradiciones étnicas en donde todo tenía una visión comunitaria (Zebadúa, 2012: 4).

Esta visión y misión institucional ha tenido eco entre los jóvenes que asisten a la Universidad Intercultural porque, para unos, representa un espacio de liberación tanto del yugo familiar como del comunitario, para otros, una oportunidad, un cúmulo de enseñanzas, y para algunos otros, una manutención, pues todos los que entran reciben una beca de mil pesos mensuales.

Yo cuando vine no sabía qué carrera estudiar, pero no me importó, me gustó mucho entrar. La vida me cambió aquí. Tengo amigos y es otra mi vida (Juanita, tsotsil, 19 años, 2009).

La UNICH resultó ser un espacio tan apropiado por los jóvenes universitarios indígenas que lo convirtieron casi en su primer espacio de socialización. La creatividad y producción juveniles han sido los motores del cambio en las identidades locales y en las relaciones interétnicas de los jóvenes de distintas etnias. Al entrar a la UNICH, estos jóvenes elevan sobremanera su consumo cultural, la mayoría compra celulares, ipods y laptops y cuidan mucho que éstos sean artefactos de moda y de alto precio pues es el estilo requerido. La mayoría se inaugura en el manejo computacional y tecnológico, todos aprenden a navegar en las redes sociales (Facebook y Twiter) y, por si fuera poco, muchos de ellos combinan estos aprendizajes con sus acarreajes culturales tradicionales porque también dentro de la UNICH: "es chido ser indígena", "aquí, en las celebraciones, nos piden hacer ritual, nos piden vestir traje", "yo aquí vine a mejorar mi lengua y mi cultura". Como la población estudiantil no sólo es indígena, la presencia mestiza y, en mucho menor medida la presencia extranjera, hace de este espacio un lugar muy diverso en el que la flexibilidad identitaria es un requisito para el contacto cultural. Devienen de este contacto estilos juveniles definidos por la mezcla. Gómez (2010) documenta varios de estos estilos: el formal o integrado, el tradicional (chamula y zinacanteca), el etnojuvenil (la mezcla tradicionalmoderno) y el alternativo (emo, dark y hippie). El estilo "etnojuvenil" es uno de los más interesantes porque devela esa transculturalidad o tránsito identitario manifiesto en términos de Willis como la "creatividad y la extensión simbólica" de un sujeto joven:

Siento que estoy normal o un poco diferente por lo que no soy igual a las otras compañeras, no ponen su traje tradicional que yo vea, por ejemplo, si yo traigo jeans lo combino con algo artesanal, no sé, quien sabe, tampoco puedo decir que soy autóctona, ni a la moda, solo siento que soy chamula ijajaja! De hecho sí me gusta combinar, por ejemplo, si el bordado de mi blusa es rosa mi faja tiene que ser rosa, acostumbro hacer eso (Gómez, 2010, Entrevista a Rosa Jiménez, 2008).

El vuelco de la política educativa cobró importancia a partir de la propuesta-exigencia zapatista, sin embargo, hay que tener presente que estos jóvenes universitarios indígenas enfrentan problemas de racismo, falta de empleo y desfase cultural, entre otros asuntos más,que la universidad misma no puede resolver. En México 
apenas se inicia la crítica sobre los alcances que pueden tener las universidades interculturales: otro asunto pendiente para los estudios culturales sobre juventudes indígenas.

\section{Apuntes finales}

Los orígenes de este sujeto histórico en Chiapas datan de 1980. Su contexto generacional se constituye con mayor fortaleza en los noventa, principalmente la segunda mitad brinda alteraciones importantes mediante cambios a nivel comercial (TLCAN), político (EZLN), musical —Café Tacuba, Santa Sabina, Manu Chau - intelectual - Immanuel Wallerstein, Pablo González Casanova, Julio Scherer- educativo - escuelas indígenas, bilingües biculturales e interculturales-, tecnológico, informático y virtual - las tecnologías de información y comunicación, TIC, las tecnologías digitales y las redes sociales sociales-. Es la estandarización de formas y estilos de vida lo que empuja a estos muchachos a dejar su comunidad, aunque fue la revolución indígena lo que les permitió la continuidad en el cambio, esto es, la permanencia consciente y decidida de elementos identitarios, lo que llama Urteaga "la voluntad de pertenencia étnica". La globalización económica requiere de este 'nuevo' sujeto: joven indígena moderno, informado, profesionalizado, cosmopolita y con una gran herencia cultural respecto a las tecnologías agrícolas. ${ }^{15}$

Las universidades interculturales son ahora los espacios educativos que esperan a estos jóvenes para formarlos y devolverlos años después a sus comunidades. Salen de la comunidad bajo la promesa de volver y ayudar a la tierra que los vio nacer; su misión es muy clara: después de recibir entrenamiento de nivel superior, el egresado de la intercultural tendrá que diseñar, gestionar y promover proyectos productivos o de gestión cultural, crear trabajos en su comunidad, detectar problemáticas y organizar a la gente para que en grupo busque la forma de autoemplearse y generar los propios insumos para su vida cotidiana y la de los suyos ivaya tarea les ha tocado a estos jóvenes! Como bola de nieve se espera que puedan acarrear los aprendizajes universitarios y contagiar a los que se quedaron. Sin embargo, esta población se está enfrentando a una disyuntiva que en el imaginario colectivo de la comunidad parece competir con gran ventaja porque, para los que no pueden salir a estudiar, la opción de migrar es "más redituable".

Con la migración y el ingreso a la escuela, la juventud se inaugura como etapa en los mundos indígenas. Es posible que desde antes existiera el reconocimiento de este período o tránsito para referirse a los segmentos de edad entre los indígenas chiapanecos. No obstante, se desconocen aún ritos de paso que inauguren este ciclo. Es posible que estos tránsitos conduzcan a la formación y al crecimiento sin adoptar decisivamente formalidades y compromisos con el mundo adulto, como antivalores definitorios que son, de lo juvenil moderno. Hacen falta etnografías que diluciden esas transiciones, períodos o procesos juveniles no vividos a la manera occidental, aunque ya hay varias reflexiones e investigaciones en marcha. ${ }^{16}$

La juventud indígena como categoría del siglo XXI se refiere a una etapa, un proceso, un resultado o una condición de vida recientemente identificada entre los pueblos indígenas y en las Ciencias Sociales. Está estructurada por los diferenciales de género y por las transiciones generacionales entre las etnias latinoamericanas. Su re-conocimiento abre una veta analítica que bien puede desarrollarse en Chiapas porque éste estado ofrece un contexto perfecto para su estudio.

En los estudios culturales la noción de joven indígena debiera referirse a un sujeto que comparte características particulares: un rango etario, un estilo de vida juvenil, prácticas juveniles y una adscripción étnica basada en la voluntad de pertenencia a su etnia. La nueva perspectiva sobre su ser juvenil indígena lo inserta en mundos menos herméticos, léase no estrictamente 
tradicionales, no decisivamente enmarcados en lógicas rurales o campesinas totalizantes, sino en 'situaciones puente', esto es, 'pendulares', porque la navegación cultural es la base para toda acción social. La nueva identidad de este joven sefavorece gracias al incremento de sus repertorios culturales y su manejo en mundos anteriormente opuestos, por ejemplo: mestizo-indígena. Los hechos previos le han permitido reconocerse y ser reconocido como un muchacho indígena moderno, identidad que las previas generaciones indígenas no experimentaron porque tampoco vivieron tales procesos, de modo que esta 'brecha' denota nuevas expectativas y visiones de mundo en las generaciones de indígenas contemporáneos.

\section{Notas}

${ }^{1}$ Las juventudes son los grupos juveniles y sus modos diversos de transitar esta etapa. En términos analíticos, la categoría se refiere a colectivos jerarquizados por una de varias condiciones sociales: etnicidad, género, clase, etc. La pluralidad del concepto abre un abanico de posibilidades para abordar la riqueza cultural que es producida por los mismos jóvenes (Duarte, 2000).

2 Aunque parece contradictorio, no lo es, porque el elemento étnico es central sólo de modo horizontal.

${ }^{3}$ La escuela de Chicago (los jóvenes de las esquinas o las bandas), la estructural-funcionalista (la cultura colegial o el joven estudiante), la gramsciana italiana (las subculturas), la francesa (las bandas y las tribus), la de Birgminhan (la resistencia y los rituales), la fontracultura (Feixa, 1998). Una actualización del estado de la cuestión la hacen Alpízar y Bernal (2003).

4 Brettel y Hollefield (2000) argumentan que el entendimiento de lo étnico como cultura estática invisibilizó la participación indígena en los estudios de migración. Ni la asociación de las etnias mexicanas a grupos culturales sin movilidad ni la salida hacia otros espacios las definió como colectivos homogéneos sin cambio.
${ }^{5}$ Algunos de estos trabajos son Juventud de una comunidad maya (Falla, 2006), Jóvenes indígenas y globalización en América Latina (Pérez Ruiz. 2008), Juventud indígena en desventaja. Cuál es el futuro de los jóvenes indios" (Pacheco, 1999), "Juventud indígena en Coyutla: construcción de identidades en el espacio rural" (García Martínez, 2003); "Lo juvenil en lo étnico. Migración juvenil indígena en la sociedad contemporánea mexicana" y "Jóvenes e indios en el México contemporáneo" (Urteaga, 2008) y "Mudándose a muchacha. La emergencia de la juventud en indígenas migrantes" (Cruz, 2009).

${ }^{6}$ En 2008, el Seminario de Estudios Jóven-es: identidades y culturas ofertado por el CIESAS-Sureste y coordinado por Diana Reartes y Tania Cruz agrupó a estudiantes de maestría trabajando con jóvenes indígenas. El resultado de aquel esfuerzo fue un conjunto de estudios pioneros sobre la materia. Entre ellos se encuentran la tesis de Ariel Corpus (2008) con jóvenes tseltales de El Corralito en Oxchuc, la de Pilar Muñoz (2009) quien analiza los mundos de vida de jóvenes tseltales de San Jerónimo Tulijá, el de Micaela Álvarez (2009) quien investiga los cambios generacionales en las mujeres indígenas tsotsiles después de la migración, y el trabajo de Irene Sánchez, quien documenta a partir la figura paradigmática del K’och, el hijo más pequeño de la familia tseltal, el modo en que el campo chiapaneco se reconfigura a partir de la migración y el incremento de los medios masivos de comunicación.

${ }^{7}$ Dos décadas más tarde, en 1970, la explosión demográfica alteña pasó de 100,000 indígenas a 200,000. En 1990, 60\% de ellos no fueron contratados pues los contratadores de mano de obra guatemalteca ya había sustituido el valor de su trabajo por menores salarios (Rus, 2002).

${ }^{8}$ En el trabajo de campo de la tesis doctoral (2005) encontré que las jóvenes indígenas, después de migrar de un espacio rural a uno urbano, reproducen un estilo de vida juvenil asociado a las prácticas del cortejo, el noviazgo y la postergación del matrimonio. El ingreso 
de las jóvenes indígenas urbanas a la universidad funciona del mismo modo y con ello se edifica un 'nuevo' paradigma de la muchacha indígena.

${ }^{9}$ En 2010 entrevisté a muchachas tsotsiles chamulas, quienes para cruzar la frontera México-Estados Unidos tuvieron que dejar la enagua y usar un pantalón. La migración indígena femenina no es nueva. Diane y Jan Rus han documentado la salida por motivos laborales de mujeres tsotsiles de comunidades de Los Altos desde 1980. En la actualidad, las chamulas están comerciando artesanías o vendiendo verduras en muchas ciudades de Chiapas o en otras de México, como Cancún y D.F. Llama la atención que las prendas distintivas del atuendo chamula, enagua y blusa brocada, se siguen usando entre estas mujeres a pesar de los climas calientes en donde trabajan, como en las playas de Chiapas - Puerto Arista o Boca del Cieloo en ciudades como Tapachula o incluso en Cancún (Cruz, 2009). Por años esto significó la continuidad cultural entre las mujeres de esta etnia porque la enagua significa estatus, adorno y feminidad. Es una prenda que cubre las partes más femeninas del cuerpo de mujer: las caderas. Usar pantalón fue y sigue siendo muy criticado entre las previas generaciones porque 'muestra' el cuerpo de la mujer. Aunque el atuendo chamula ha tenido cambios en el diseño a través de los años, el abandono de la enagua por las chamulas que están en Florida representa ya una ruptura que ni la conquista logró. Ahora vemos que las búsquedas de las muchachas indígenas son otras. La migración y los medios de comunicación están colaborando insistentemente con estos cambios culturales que percibimos.

${ }^{10}$ Los estudios clásicos de juventud lo demostraron en su momento (Parsons, 1949; Coleman, 1961). Parsons (1949) anunció la existencia de una 'cultura juvenil' formada por jóvenes estudiantes quienes cuasirepresentaban una clase social a partir de la edad y el sexo en la estructura social estadounidense. La edad, la clase y el género fueron categorías que ayudaron a Parsons a desarrollar el concepto 'cultura juvenil'. Para él, esta cultura era homogénea y representativa de la nueva ola generacional. En diálogo con Parsons, James Coleman (1961) realizó un estudio con jóvenes estudiantes norteamericanos y mostró cómo la industrialización requirió de la escuela como institución para acoger a los jóvenes y prepararlos antes de entrar a la adultez, un asunto de mera lógica económica capitalista. Basado en una encuesta levantada en nueve preparatorias, Coleman detectó el surgimiento de la cultura adolescente en la época industrial, aquello que ya había señalado Hall a principios de siglo XX (1905).

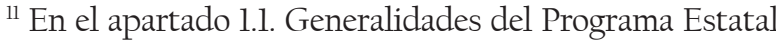
de Fortalecimiento de Telesecundaria en Chiapas (2012), se estipula que en "el ciclo escolar 1980-1981 se crearon los primeros 31 centros educativos con una matrícula docente de 38 profesionistas de diversas áreas, con una inscripción de 970 alumnos ubicados en localidades rurales".

${ }^{12}$ Para Pacheco (2012) la comunidad es la institución más fuerte para transitar a la vida adulta entre los jóvenes wixarikas del occidente de México. Con la llegada de la escuela se imponen otras lógicas temporales que hacen 'desaprender la cultural wixarika y malaprender la cultura mestiza'.

${ }^{13}$ Esto cambió mucho desde la crisis agrícola de los ochenta con la participación laboral femenina de mujeres indígenas, quienes con su ingreso y gestión crearon nuevas jefaturas de hogar (Rus et al., 2002).

${ }^{14}$ Otras universidades previas y posteriores a la UNICH y con tónicas parecidas, aunque alejadas del programa estatal y por ello con menor presupuesto, son la Universidad Tecnológica de la Selva, la Universidad de Los Altos y la Universidad de la Tierra.

15 'La juventud indígena' como categoría social es hija del capitalismo tardío, al modo en que 'la juventud rural' lo fue cuando sucedió la expansión de las relaciones de producción al campo. Los jóvenes indígenas son el 'combustible' para la producción agrícola e industrial de zonas específicas dentro de México y fuera de él 
(Pacheco, 1999; Cruz, 2011). Desde el siglo XIX en Europa, las políticas estatales estuvieron orientadas a la inversión en la educación de generaciones de jóvenes rurales para enculturarlos y acelerar los procesos de transformación tecnológica. Así se construyeron escuelas agrícolas y se desarrollaron tecnologías de la agricultura moderna. El objetivo fue modernizar las estructuras productivas y educar a las nuevas generaciones, un instrumento político-económico que permitiría crear condiciones objetivas para que los jóvenes rurales fueran agentes del cambio dentro de sus comunidades. Enfocado a la autogestión comunitaria, aunque siempre con inversión estatal, este adiestramiento generacional tuvo lugar posteriormente en Estados Unidos y después en América Latina (Belviqua, 2009).

16 Alumnos de posgrado no sólo de Centros de Investigación en México —CIESAS, COLMEX — sino de varias universidades latinoamericanas - UADY, ENAH, UNACH, UASLP, UNIVERSIDAD DE MANIZALESestán realizando trabajos al respecto.

\section{Bibliografía}

Alpízar y Bernal (2003), "La construcción social de las juventudes”, en Última Década, núm. 19, pp. 105-123.

Aquino Moreschi, Alejandra (2009), "Entre el «sueño zapatista» y el «sueño americano»: la migración a Estados Unidos vista desde las comunidades zapatistas", en Migración y Desarrollo, Segundo Semestre, pp. 79-95.

Aries, P. (1990) El niño y la vida familiar en el antiguo régimen, Madrid: Taurus.

Bastiani Gómez, José, Lorena Ruíz-Montoya, Erin Estrada Lugo, Tania Cruz Salazar y José Antonio Aparicio Quintanilla (2012), "Políticaeducativaindígena. Práctica docente, castellanización, burocracia y centralización de la educación como limitaciones del éxito pedagógico en la región Ch'ol, Chiapas", en Revista Perfiles Educativos, vol. XXXIV, núm. 135, IISUE/UNAM, pp. 8-25.
Bevilqua Marin, Joel Orlando (2009), “Juventud rural: una invención de capitalismo industrial", en Revista Estudios Sociológicos, vol. V, 27, núm. 80, mayo-agosto, pp. 619-653.

Brettel, Caroline B. y James F. Hollefield (eds.) (2000), Migration Theory: Talking Across Disciplines, Nueva York y Londres: Roudledge.

Camacho Velázquez y Arturo Lomelí (2009), "Procesos migratorios de chiapanecos hacia el norte: causas y consecuencias", en Freyermuth-Enciso, Graciela y Sergio Meneses De crianzas, jaibas e infecciones. Indígenas del sureste en la migración, México: CIESAS, pp. 81-107.

Coleman, James S. (1961), The Adolescent Society. The Social Life of the Teenager and Its Impact on Education, Nueva York, EUA: The Free Press of Glencoe, pp. 1-5l.

Cruz Salazar, Tania (2009), "Mudándose a muchacha. La emergencia de la juventud en indígenas migrantes", en Freyermuth-Enciso, Graciela y Sergio Meneses, De crianzas, jaibas e infecciones. Indígenas del sureste en la migración, México: CIESAS, pp. 169-212.

Cruz Salazar, Tania (2012a), "La norteada juvenil. Representaciones de la migración tzotzil", en Rashkin, E. y N. E. García Meza, (eds.), Escenarios de la cultura y la comunicación en México. De la memoria al devenir cultural, México: Universidad Veracruzana, núm. 3, pp. 9-89.

Cruz Salazar, Tania (2012b), "Transnational Subjectivities: Mayas from Chiapas in California”, en Vélez-Ibáñez, Carlos y Roberto Sánchez (coords.), Visiones de Acá y Allá: Las implicaciones de la nueva legislación anti-immingrante a las comunidades Mexicanas y Latinas, Arizona: Porrúa/Universidad Autónoma de Ciudad Juáres/Arizona State University, en prensa.

Cruz Salazar, Tania (2012), "La juventud indígena de Chiapas en California", manuscrito.

Donati, Pier Paolo (1999), "Familias y generaciones", en Desacatos, otoño, núm. 002, México: CIESAS-DF, pp. 27-49.

Duarte, Klaudio (2000), “ijuventud o juventudes? Acerca de cómo mirar y remirar a las juventudes de nuestro 
continente", en Última Década, septiembre, núm. 13 , México: CIDPA, pp. 59-77.

Falla, Ricardo (2006), Juventud de una comunidad maya, Ixcán, Guatemala, Guatemala: Editorial Universitaria.

Falla, Ricardo (2008), Migración internacional retornada. Juventud indígena de Zacualpa, Guatemala, Guatemala: Avancso.

Feixa, Carles (1998), El reloj de arena. Culturas juveniles en México, México: Causa Joven/SEP.

Feixa, Carles (2006), "Generación XX. Teorías sobre la juventud en la era contemporánea", en Revista Latinoamericana de Ciencias Sociales Niñezy Juventud, núm. 2, vol. 4, enero-junio, pp. 1-18.

Fox, Jonathan y Libby Haight (2010), "La política agrícola mexicana: metas múltiples e intereses en conflicto" en Fox, Jonathan y Libby Haight (coords.), Subsidios para la desigualdad. Políticas públicas del maíz en México a partir del libre comercio, Woodrow Wilson International Center for Scholars/CIDE/UCSC, pp. 9-45.

Foley, Douglas y Dorothy C. Holland (1996), "The Silent Indian as a Cultural Production”, en Bradley, Levinson, Douglas Foley y Dorothy C. Holland, The cultural production of the educated person. Critical ethnographies of schooling and local practice, New York: State University of New York, pp. 79-91.

Gama, Federico (2008), "Mazahuacholoskatopunk: la identidad urbana de los jóvenes indígenas y rurales en la ciudad de México", en Jóvenes. Revista de estudios sobre juventud, núm. 27, enero-junio, pp. 26-54.

García, Ariel (2009), "Juventud indígena en el Totonacapan veracruzano", ponencia, Primer Encuentro Nacional sobre Comunicación y Juventud "Los jóvenes en el mundo contemporáneo", 3-9 de noviembre, Universidad Autónoma de Yucatán.

González Cangas, Yanko (2004), "Juventud rural: trayectorias teóricas y dilemas identitarios," en Nueva Antropología, pp. 153-175.

Gómez Díaz, Clara (2010), "Estilos juveniles y consumo cultural en la Universidad Intercultural de Chiapas" Tesis de licenciatura, México: UNACH.
Hall, S. G. (1915), Adolescence: Its Psychology and its relations to Psysiology, Sociology, Sex, Crime, Religion and Education, Nueva York: Appleon Century Crofts.

Hernández Silvano, Amadeo (2012), Discriminación y racismo en la práctica educativa de una escuela intercultural: El caso de la Escuela Secundaria Técnica. \# 62 de Damasco, Ocosingo, Chiapas. Tesis de Maestría, UPN.

Hvostoff, Sophie (2009), "La comunidad abandonada. La invención de una nueva indignidad urbana en las zonas periféricas Tzotziles y Tzeltales de San Cristóbal de Las Casas, Chiapas, México (1974-2001)", en Estrada Saavedra, Marco (eds.) Chiapas después de la tormenta. Estudios sobre economía, sociedad y política, El Colegio de México/Gobierno del Estados de Chiapas/Cámara de Diputados LX Legislatura.

Leyva Solano, Xochitl y Gabriel Ascencio Franco (2002), Lacandonia al filo del agua, México: CIESAS/ Universidad Nacional Autónoma de MéxicoPrograma de Investigaciones Multidisciplinarias Sobre Mesoamérica y el Sureste/Fondo de Cultura Económica.

Mancina, Peter (2011), "Crisis-management: TzeltalMaya transnational migration and the Foucauldian apparatus", en Dialectical Anthropology, 17 de febrero, pp. 1-21.

Margulis, Mario et al. (1994) La cultura de la noche: la vida nocturna de los jóvenes en Buenos Aires, Buenos Aires: Biblos.

Margulis, Mario y Marcelo Urresti (1996), "La juventud es más que una palabra”, en Margulis, Mario (ed.), La juventud es más que una palabra. Ensayos sobre cultura y juventud, Buenos Aires: Editorial Biblos Sociedad, pp. 13-30.

Mead, M. (1985), Adolescencia, sexo y cultura en Samoa, Barcelona: Planeta.

Muñoz, María del Pilar (2009), Expectativas de vida entre jóvenes de una comunidad tseltal: San Jerónimo Tulijá, tesis de maestría, CIESAS-Sureste. 
Pacheco, Lourdes (1997), "La doble cotidianeidad de los Huicholes jóvenes. Aportaciones sobre la identidad juvenil desde la etnografía", en Jóvenes, núm. 4, México, pp. 100-112.

Pacheco, Lourdes (1999), "Juventud indígena en desventaja. ¿Cuál es el futuro de los jóvenes indios?", en Jóvenes, Nueva Época, año 3, núm. 9, julio-diciembre, pp. 24-39.

Pacheco, Lourdes (2012), “¿Qué significa para los jóvenes indígenas estar aquí? Continuidades y alteridades en la juventud wixarika en el occidente de México", en Ponencia ICA.

Pérez Islas, J.A y M. Urteaga (coords.) (2004), Historias de los jóvenes en México: Su presencia en el siglo XX, México: Secretaría de Educación Pública/Instituto Mexicano de la Juventud/Archivo General de la Nación.

Pérez Islas, J. A. (2006), "Trazos para un mapa de la investigación sobre juventud en América Latina”, en Papers 79, pp. 145-170.

Pérez Ruíz, Maya Lorena (coord.) (2008), Jóvenes indígenas y globalización en América Latina, Colección Científica, México: Instituto Nacional de Antropología e Historia, pp. 286.

Rus, Jan (2010), The End of the Plantations and the Transformation of Indigenous Society in Highland Chiapas, 1974-2009, Dissertation, Mexico: University of California, Riverside.

Rus, Jan et al. (2002), Tierra, libertad y autonomía: impactos regionales del zapatismo en Chiapas, México: CIESAS/IWGIA.
Ruiz Lagier, Verónica (2007), "Las nuevas formas en que los migueleños viven la juventud. El caso de La Gloria", en Camus, Manuela (ed.), Comunidades en Movimiento. La migración internacional en el norte de Huehuetenango, Guatemala: Instituto Centroamericano de Estudios Sociales y Desarrollo (INCIDES)/ Centro de Documentación de la Frontera Occidental (CEDFOG).

Sánchez, Irene (2009), Entre arraigo y movilidad: el Xut en la familia tseltal contemporánea de El Corralito, Oxchuc, Chiapas, tesis de maestría, San Cristóbal de Las Casas, Chiapas, México: CIESAS, pp. 108.

Talcott, Parsons (1942), "Age and sex in the social structure of the United States", en American Sociological Review (octubre).

Urteaga Castro Pozo, Maritza (2008), "Lo juvenil en lo étnico. Migración juvenil indígena en la sociedad contemporánea mexicana", en Revista Ponto e Vírgula, núm. 4, pp. 261-275.

Villafuerte Solís, Daniel y María del Carmen García Aguilar (2006), "Crisis rural y migraciones en Chiapas", en Migración y Desarrollo, primer semestre, pp. 102-130.

Zebadúa Carbonell, Juan Pablo (2012), “iJuventudes interculturales? Nuevas formas epistemológicas para entender las identidades juveniles rurales $\mathrm{y} / \mathrm{o}$ indígenas", Ponencia ICA. 